\title{
Performansi Response Time Query Pada Hadoop-Hive Menggunakan Metode Partition
}

\author{
Marwan $^{1)}$, Zawiyah Saharuna ${ }^{2)}$ Rini Nur ${ }^{3)}$ \\ 1,2,3 Teknik Elektro, Politeknik Negeri Ujung Pandang, \\ email:marwan.elektro16@gmail.com ${ }^{1}$, zawiyah@poliupg.ac.id ${ }^{2}$, rini@poliupg.ac.id ${ }^{3}$
}

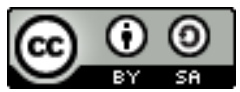

Abstract

Hive menggantikan teknik pemrosesan tradisional RDBMS yang tidak dapat digunakan pada big data. Tetapi, Hive dengan kondisi default akan mencari data secara menyeluruh saat mengeksekusi query. Metode partition mampu mengelompokkan data, sehingga dilakukan pengujian untuk mengetahui apakah dengan mengelompokkan data akan memberikan peningkatan performansi response time query atau sebaliknya. Pada penelitian ini, dibangun infrastruktur Hadoop cluster dengan sistem multi node menggunakan virtual machine. Dataset yang digunakan adalah dataset Movielens dengan kardinalitas atribut yaitu 5, 50 dan 100. Tiap dataset terdiri dari 15 juta records data. Berdasarkan hasil penelitian, metode partition selain mampu mengelompokkan data juga memberikan performansi response time query yang lebih cepat sebesar $30.8 \%$ dibandingkan kondisi default. Selain itu, Metode partition saat kardinalitas 100 lebih baik dibandingkan dua kardinalitas yang lebih kecil yaitu kardinalitas 5 dan kardinalitas 50 .

Keywords: Big Data, Hadoop, Hive, Partition.

\section{PENDAHULUAN}

Pengelolaan big data yang berukuran hingga petabyte, membuat teknik pemrosesan tradisional seperti Relational Database Management System (RDBMS) tidak dapat lagi digunakan [1]. Saat ini, sistem platform yang dikenal untuk mengelola big data yaitu Hadoop. Hadoop adalah platform yang sangat mendukung untuk melakukan pengelolaan big data secara terdistribusi dengan melibatkan berkluster-kluster komputer [2]. Salah satu ekosistem dari Hadoop untuk menggantikan teknik pemrosesan tradisional pada big data adalah Hive.

Hive adalah sebuah solusi platform opensource data warehousing untuk pengguna mampu mengelola big data yang ada pada Hadoop Distributed File System (HDFS). Data warehousing merupakan sistem yang mengambil (retrieve) dan mengkonsolidasikan (consolidate) data secara periodik (periodically) dari sumber data ke dalam penyimpanan dimensional dan ternormalisasi. Hive sebagai data warehousing yang andal saat ini menyederhanakan pengelolaan dataset pada Hadoop cluster karena mendukung bahasa yang familiar dengan Structured Query Language (SQL) yang disebut dengan istilah HiveQL. Hive menjadi sangat populer di kalangan non-programmer karena menghilangkan kebutuhan untuk menulis program Mapreduce yang kompleks [3].
Penelitian sebelumnya telah dilakukan oleh Ashwitha (2017) untuk menganalisis dataset pada Hadoop cluster menggunakan Hive. Akan tetapi, penelitian Ashwitha belum membahas terkait pengujian performansi response time query menggunakan metode partition [4]. Metode partition akan mengelompokkan data berdasarkan kardinalitas atribut. Metode tersebut adalah metode yang efisien untuk memberikan struktur data yang ekstra pada Hive [5]. Hal ini penting diteliti untuk menganalisis apakah dengan struktur data yang telah dikelompokkan akan memberikan peningkatan performansi dalam mengeksekusi query dalam big data atau tidak. Jika data sedikit, tidak akan menimbulkan permasalahan, akan tetapi jika datanya mencapai jutaan atau puluhan juta records, akan menimbulkan permasalahan yaitu lamanya waktu pencarian data. Berdasarkan masalah yang telah dibahas diatas, maka penelitian ini melakukan pengujian performansi response time query berdasarkan metode partition.

\section{KAJIAN LITERATUR}

\section{A. Big Data}

Big data didefinisikan sebagai fenomena yang ditandai dengan adanya peningkatan volume yang sedang berlangsung, variasi, kecepatan dan kebenaran data yang membutuhkan teknologi yang canggih untuk dilakukan penangkapan, penyimpanan, pendistribusian, pengelolaan dan 
penganalisisan suatu data yang besar [6]. Big data adalah sebuah istilah yang digunakan untuk menjelaskan data dengan ukuran yang besar disertai dengan volume yang akan terus bertambah.

B. Hadoop

Hadoop diciptakan sebagai software framework dengan melibatkan berklusterkluster komputer, artinya mampu menghubungkan beberapa komputer untuk dapat bekerja sama dalam hal menyimpan dan mengelola big data. Ketika penggunaan data melonjak tajam, komputer pada cluster tidak kewalahan karena tidak satu komputer saja yang akan mengurus data tetapi ada 2 atau lebih yang akan memproses data pada saat yang sama.

C. Hive

Hive merupakan apache open source data warehousing untuk Hadoop. Fungsi utama dari Hive adalah diciptakan untuk menyediakan data summarization, query dan analisis dataset yang besar [7].

\section{Partition}

Hive mengatur tabel dalam bentuk partition untuk mengelompokkan data yang sama menjadi beberapa bagian berdasarkan uniq values dari atribut [8]. Dalam banyak hal, skema partition ini mirip dengan apa yang disebut sebagai partition oleh banyak vendor database, tetapi terdapat perbedaan dimana nilai partition key disimpan dengan metadata dan bukan dengan data [9].

\section{METODE PENELITIAN}

Metode dalam penelitian diperlukan agar serangkaian kegiatan menjadi teratur dan sistematis sehingga hasil yang diperoleh sesuai dengan tujuan dari sebuah penelitian. Adapun tahapan penelitian seperti pada Gambar 1 berikut.

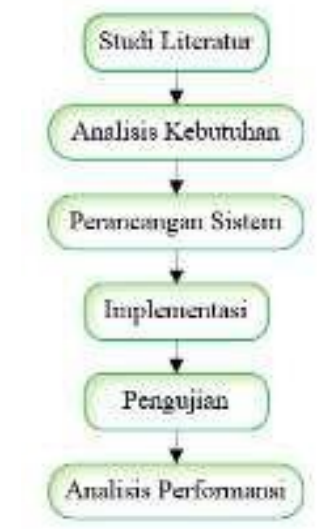

Gambar 1. Metode Penelitian
A. Studi Literatur

Tahapan penelitian dimulai dengan studi literatur. Studi literatur dilakukan untuk memahami konsep dan karakteristik big data serta platform Hadoop dan Hive terutama metode partition melalui pustaka-pustaka yang berkaitan dengan penelitian, berupa buku, jurnal dan skripsi ataupun via web. Pada tahapan ini dilakukan identifikasi terhadap permasalahan, serta rancangan skenario yang menjadi dasar dilakukannya sebuah penelitian.

B. Analisis Kebutuhan

Tahapan kedua adalah tahapan analisis kebutuhan. Analisis kebutuhan bertujuan untuk mengumpulkan informasi perangkat keras (hardware), perangkat lunak (software) serta bahan dataset yang dibutuhkan dalam penelitian. Pada tahap ini diperoleh perangkat keras (hardware) dan perangkat lunak (software) yang dibutuhkan adalah sebagai berikut:

1) 1 unit Personal Computer (PC), Memory RAM 12 GB, Sistem Operasi Windows 10 Pro, Processor Core i5.

2) Oracle VM VirtualBox

3) Sistem Operasi Ubuntu Server

4) Putty

5) JavaKit 8

6) $\mathrm{Ssh}$

7) Hadoop 2.8.0

8) Hive 1.2.1

9) WinsCP

Adapun untuk kebutuhan dataset yang digunakan dalam penenlitian ini berasal dari situs website penyedia dataset Movielens. Dataset Movielens adalah data yang berisikan informasi user yang telah memberikan rating pada sebuah judul film beserta data identitas diri dari user. Dataset ini terdiri dari tiga file dataset yaitu : file dataset ratings, file dataset users dan file dataset movies. Dataset akan dilakukan penggabungan dari tiga file dataset menjadi satu file data menggunakan Hive Query Language (HiveQL). Dataset yang digunakan untuk pengujian adalah data dengan kardinalitas atribut userid yaitu 5, 50 dan 100. Tiap dataset terdiri dari 15.000 .000 records data.

C. Perancangan Sistem

Tahapan perancangan sistem adalah tahapan bagaimana melakukan sebuah penelitian secara teknis untuk mencapai tujuan penelitian. Dari tahapan hasil studi literatur dan analisis kebutuhan, diambil simpulan dari beberapa sumber untuk menentukan model 
sistem untuk penelitian. Model sistem yang dirancang terlihat pada Gambar 2 berikut:

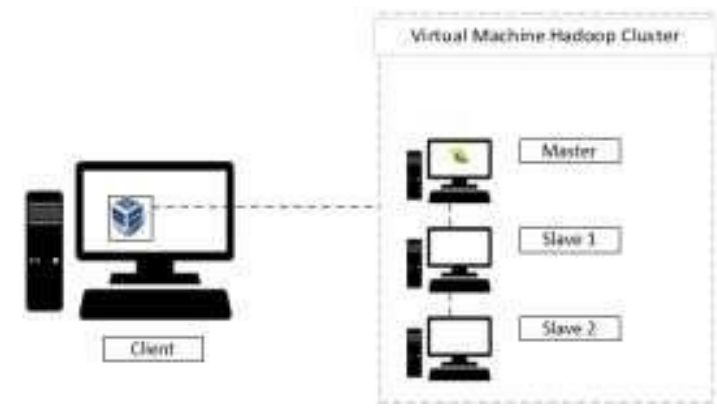

Gambar 2. Infrastruktur Hadoop Cluster

Adapun alur proses request data saat melakukan eksekusi query dari Hive adalah sebagai berikut:

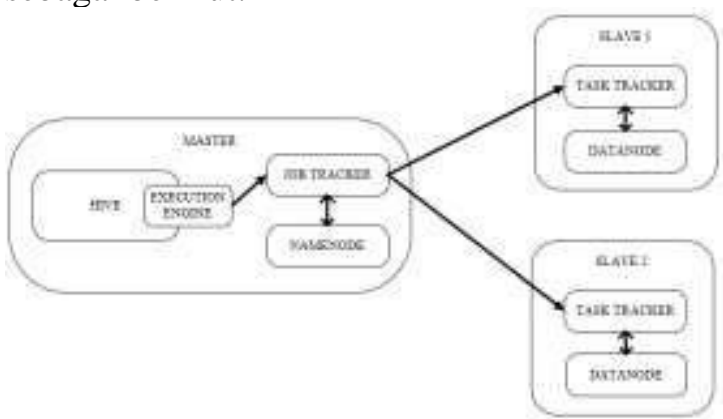

Gambar 3. Alur Proses Request Data saat Eksekusi

Query

Perancangan model query yang akan dijadikan sebagai bahan uji dalam penelitian ini adalah didasarkan pada atribut userid yang dijadikan sebagai bahan untuk menerapkan metode partition, sehingga eksekusi query yang dilakukan berdasarkan uniq values dari atribut tersebut.

D. Implementasi

Tahapan ini adalah sebagai penerapan model sistem yang telah dirancang dengan tujuan agar sistem dapat beroperasi dengan baik dalam menjalankan skenario pengujian. Tahapan ini dimulai dengan penginstalan Oracle Vm VirtualBox hingga instalasi dan konfigurasi pada Hadoop dan Hive.

E. Pengujian

Tahap pengujian adalah tahapan untuk mengetahui perfomansi response time query pada metode partition. Secara umum, tahapan pengujian adalah sebagai berikut:

a) Skenario Pertama

Skenario pertama bertujuan untuk menguji performansi response time query pada metode partition dengan membandingkannya dengan kondisi default. Berikut kondisi pengujian pada skenario pertama menggunakan data kardinalitas 5:

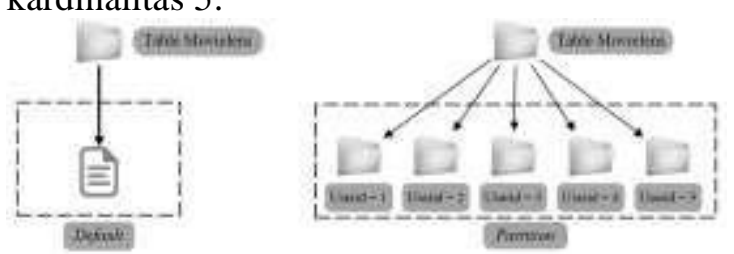

Gambar 4. Kondisi Pengujian pada Skenario Pertama

Pengujian dilakukan sebanyak 5 kali. Data hasil pengujian selanjutnya diinputkan kedalam tabel dan disajikan dalam bentuk grafik.

b) Skenario Kedua

Skenario kedua bertujuan untuk menguji performansi response tme query berdasarkan variasi kardinalitas pada metode partition. Hal ini dilakukan untuk melihat apakah variasi kardinalitas berpengaruh atau tidak terhadap performansi response time query pada metode partition. Pengujian dimulai pada kardinalitas 5 , kemudian dilakukan pengujian pada kardinalitas 50, dan terakhir pada data kardinalitas 100. Berikut kondisi pengujian pada skenario kedua:

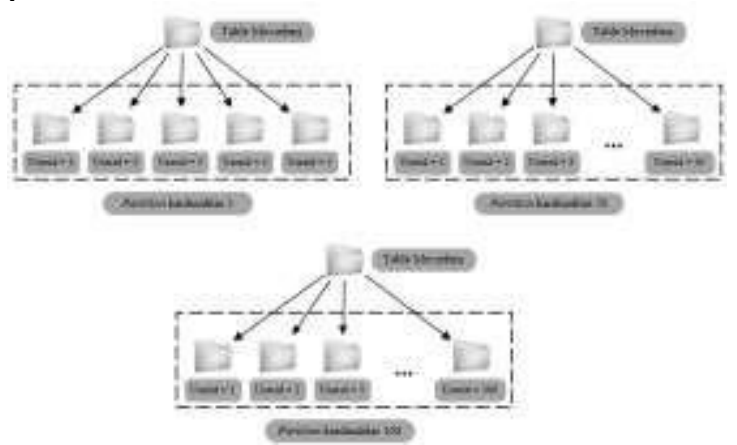

Gambar 5. Kondisi Pengujian pada Skenario Kedua

Pengujian dilakukan sebanyak 5 kali. Data hasil pengujian selanjutnya diinputkan kedalam tabel dan disajikan dalam bentuk grafik.

F. Analisis Performansi

Pada tahap ini dilakukan analisis performansi dari hasil pengujian yang telah didapatkan selama penelitian dan selanjutnya akan menghasilkan sebuah kesimpulan dari penelitian ini.

\section{HASIL DAN PEMBAHASAN}

A. Import Dataset ke Hadoop Cluster 

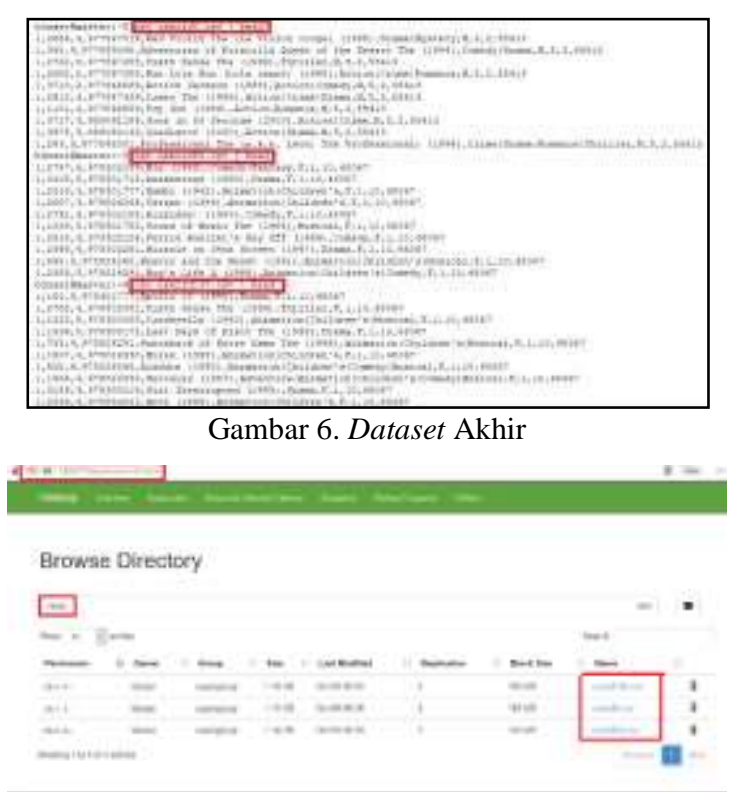

Gambar 7. Tampilan pada HDFS

B. Implementasi Data pada Hive

1) Implementasi Data pada Kondisi Default

Implementasi data pada kondisi default diawali dengan membuat metadata kondisi default pada Hive seperti Gambar 8 berikut:

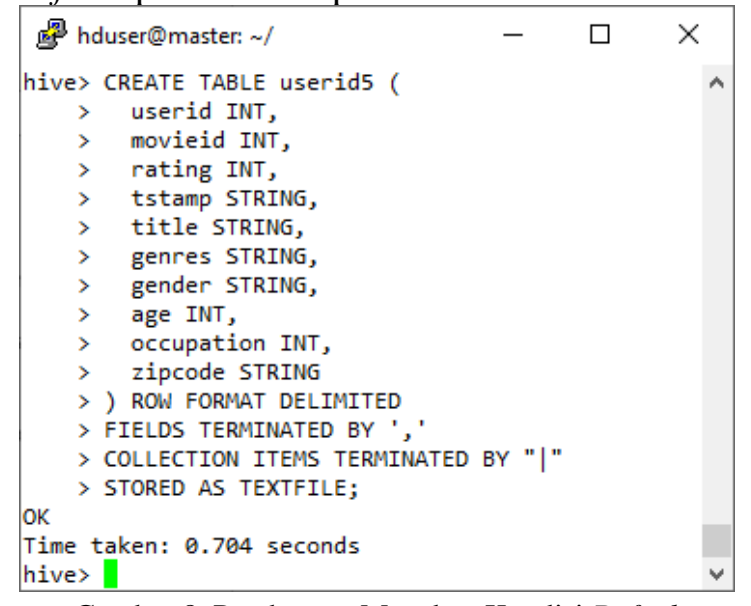

Gambar 8. Pembuatan Metadata Kondisi Default

Kemudian dilakukan load data dari file dataset yang telah ada di direktori /data ke direktori kondisi default menggunakan statement atau query seperti pada Gambar 9 dibawah:

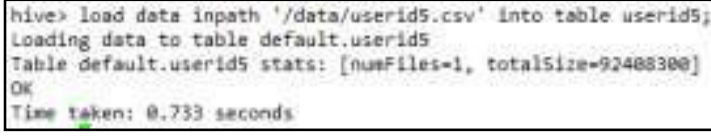

Gambar 9. Load Data pada Kondisi Default

Keberhasilan dalam melakukan load data dibuktikan dengan berpindahnya file dataset ke direktori kondisi default seperti Gambar 10 berikut:

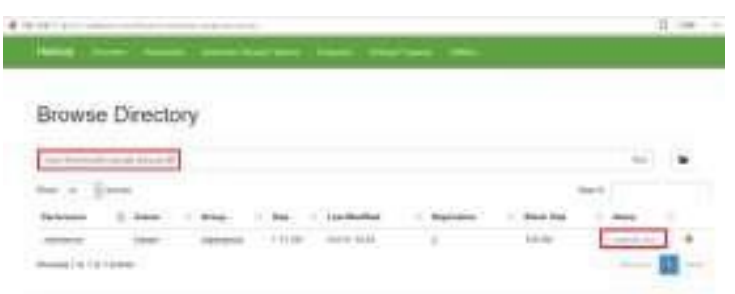

Gambar 10. Tampilan Direktori Kondisi Default

Selanjutnya, untuk implementasi data pada kondisi default untuk kardinalitas 50 dan kardinalitas 100 menggunakan cara yang sama pada implementasi kardinalitas 5 yang dilakukan diatas.

2) Implementasi Data pada Kondisi Partition Implementasi data pada kondisi partition diawali dengan membuat metadata kondisi partition seperti Gambar 11 berikut:

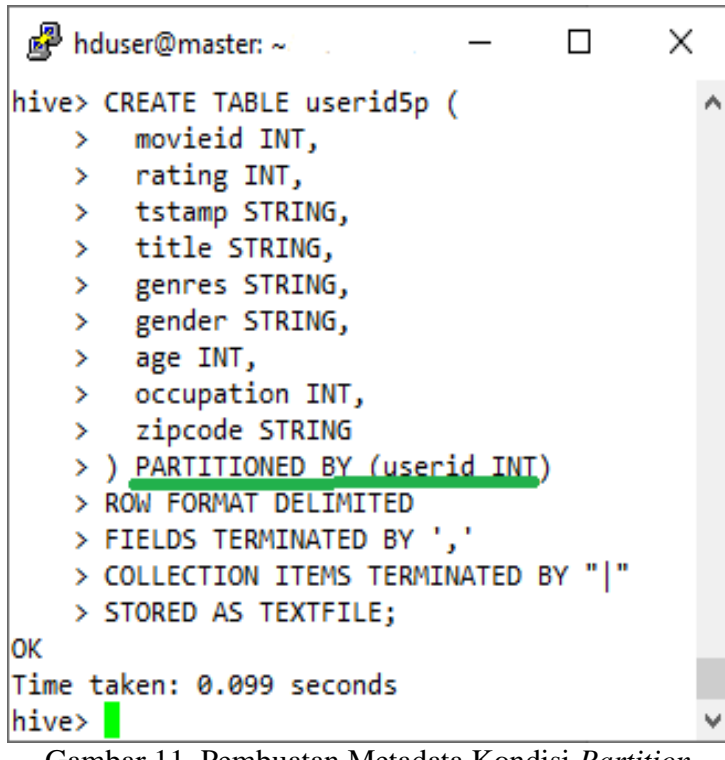

Gambar 11. Pembuatan Metadata Kondisi Partition

Sebelum melakukan insert data ke tabel dengan metode partition, konfigurasi parameter yang diberikan dibawah harus di set pada Hive shell:

hive> set hive.exec.dynamic.partition .mode=nonstrict;

Kemudian dilakukan insert data dari file data yang telah ada di direktori kondisi default menuju ke kondisi partition dengan menggunakan statement atau query seperti pada Gambar 12 berikut: 


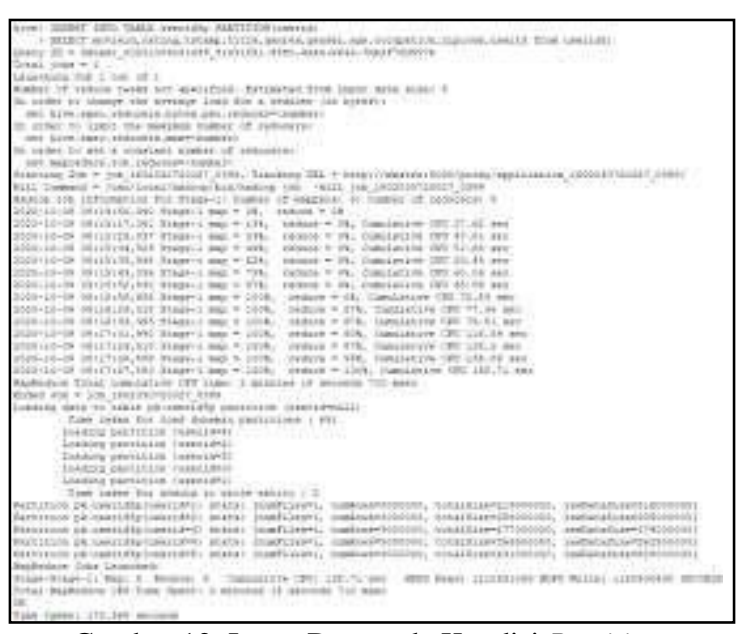

Gambar 12. Insert Data pada Kondisi Partition

Keberhasilan dalam melakukan insert data dibuktikan dengan terbentuknya direktori berdasarkan kardinalitas atribut userid yaitu 5 seperti pada Gambar 13 berikut:
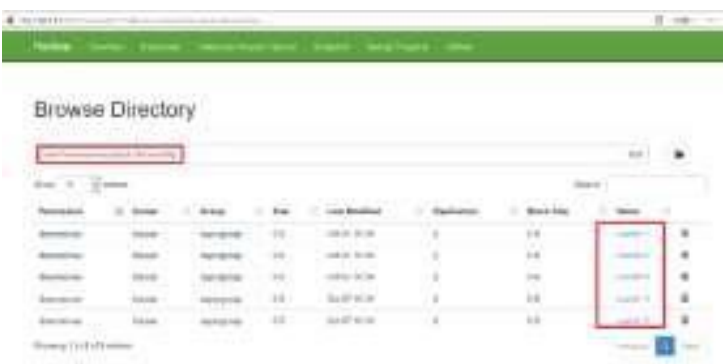

Gambar 13. Tampilan Direktori Kondisi Partition

Selanjutnya, untuk implementasi data pada kondisi partition untuk kardinalitas 50 dan kardinalitas 100 menggunakan cara yang sama pada implementasi kardinalitas 5 yang dilakukan diatas.

C. Hasil Pengujian Performansi

Hasil dari pengujian performansi response time query yang telah dilakukan adalah sebagai berikut:

1) Hasil Skenario Pertama

Tabel 1. Hasil Pengujian Skenario Pertama

\begin{tabular}{cccccc}
\hline \multirow{2}{*}{$\begin{array}{c}\text { Skenario } \\
\text { Partition }\end{array}$} & \multicolumn{5}{c}{$\begin{array}{c}\text { Rata-rata Response Time (s) } \\
\text { Model Query }\end{array}$} \\
& $\mathbf{Q 1}$ & $\mathbf{Q 2}$ & $\mathbf{Q 3}$ & $\mathbf{Q 4}$ & $\mathbf{Q 5}$ \\
\hline \multirow{2}{*}{ Default } & 39.54 & 38.68 & 39.59 & 39.32 & 38.45 \\
& 34 & 36 & 58 & 48 & 88 \\
\hline \multirow{2}{*}{ Partition } & 27.03 & 26.05 & 27.87 & 27.33 & 27.07 \\
& 72 & 32 & 14 & 8 & 18 \\
\hline
\end{tabular}

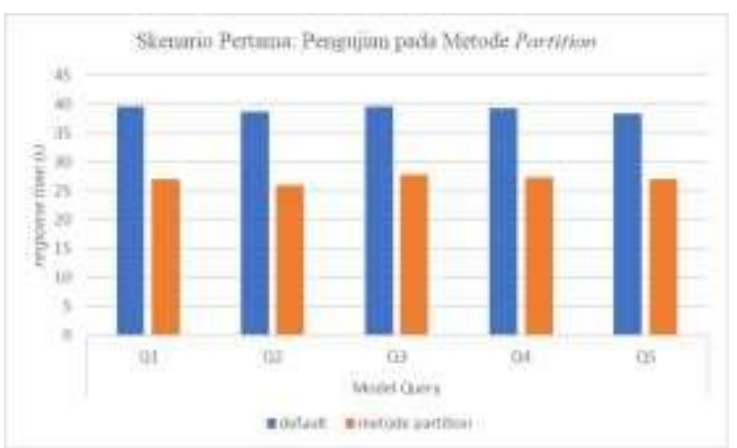

Gambar 14. Diagram Hasil Pengujian Skenario Pertama

Tabel 2. Keterangan Model Query Skenario Pertama

\begin{tabular}{|c|c|c|c|}
\hline $\begin{array}{l}\text { Model } \\
\text { Query }\end{array}$ & Kondisi & Query & $\begin{array}{l}\text { Output } \\
\text { (records) }\end{array}$ \\
\hline \multirow{2}{*}{ Q1 } & default & $\begin{array}{l}\text { select count }(*) \text { from } \\
\text { userid5 where } \\
\text { userid=1; }\end{array}$ & 3.000 .000 \\
\hline & partition & $\begin{array}{l}\text { select count }(*) \text { from } \\
\text { userid5p where } \\
\text { userid=1; }\end{array}$ & 3.000 .000 \\
\hline \multirow{3}{*}{ Q2 } & default & $\begin{array}{l}\text { select count }\left(^{*}\right) \text { from } \\
\text { userid5 where }\end{array}$ & 3.000 .000 \\
\hline & & $\begin{array}{l}\text { userid=2; } \\
\text { select } \operatorname{count}(*) \text { from }\end{array}$ & \\
\hline & partition & $\begin{array}{l}\text { userid } 5 p \text { where } \\
\text { userid=2; }\end{array}$ & 3.000 .000 \\
\hline \multirow{3}{*}{ Q3 } & default & $\begin{array}{l}\text { select count }(*) \text { from } \\
\text { userid5 where }\end{array}$ & 3.000 .000 \\
\hline & & $\begin{array}{l}\text { userid=3; } \\
\text { select } \operatorname{count}(*) \text { from }\end{array}$ & \\
\hline & partition & $\begin{array}{l}\text { userid } 5 \mathrm{p} \text { where } \\
\text { userid }=3\end{array}$ & 3.000 .000 \\
\hline \multirow{3}{*}{ Q4 } & default & $\begin{array}{l}\text { select count }\left(^{*}\right) \text { from } \\
\text { userid5 where }\end{array}$ & 3.000 .000 \\
\hline & & select count $(*)$ from & \\
\hline & partition & $\begin{array}{l}\text { userid5p where } \\
\text { userid=4; }\end{array}$ & 3.000 .000 \\
\hline \multirow{3}{*}{ Q5 } & default & $\begin{array}{l}\text { select count }(*) \text { from } \\
\text { userid5 where }\end{array}$ & 3.000 .000 \\
\hline & & $\begin{array}{l}\text { userid=5; } \\
\text { select count } * \text { from }\end{array}$ & \\
\hline & partition & $\begin{array}{l}\text { userid5p where } \\
\text { userid=5; }\end{array}$ & 3.000 .000 \\
\hline
\end{tabular}

Dari pengujian yang telah dilakukan, pada Gambar 14 terlihat bahwa metode partition selain mampu mengelompokkan data, juga memberikan performansi response time yang lebih cepat dibandingkan dengan mengeksekusi query pada kondisi default. Persentase rata-rata response time query pada metode partition mengalami penurunan sebesar $30.8 \%$ dari kondisi default.

2) Hasil Skenario Kedua

Tabel 3. Hasil Pengujian Skenario Kedua

\begin{tabular}{cccccc}
\hline $\begin{array}{c}\text { Variasi } \\
\text { Kardinalitas }\end{array}$ & Q1 & Q2 & Q3 & Q4 & Q5 \\
& Model Query \\
\hline \multirow{2}{*}{ kardinalitas 5 } & 27.45 & 26.14 & 28.12 & 28.27 & 28.63 \\
& 8 & 56 & 26 & 3 & 94 \\
\hline \multirow{2}{*}{ kardinalitas 50 } & 26.19 & 26.03 & 26.03 & 26.17 & 25.94 \\
& 86 & 5 & 56 & 14 & 1 \\
\hline
\end{tabular}




\begin{tabular}{cccccc} 
kardinalitas & 25.66 & 25.68 & 25.80 & 25.82 & 25.77 \\
100 & 66 & 4 & 66 & 22 & 76 \\
\hline
\end{tabular}




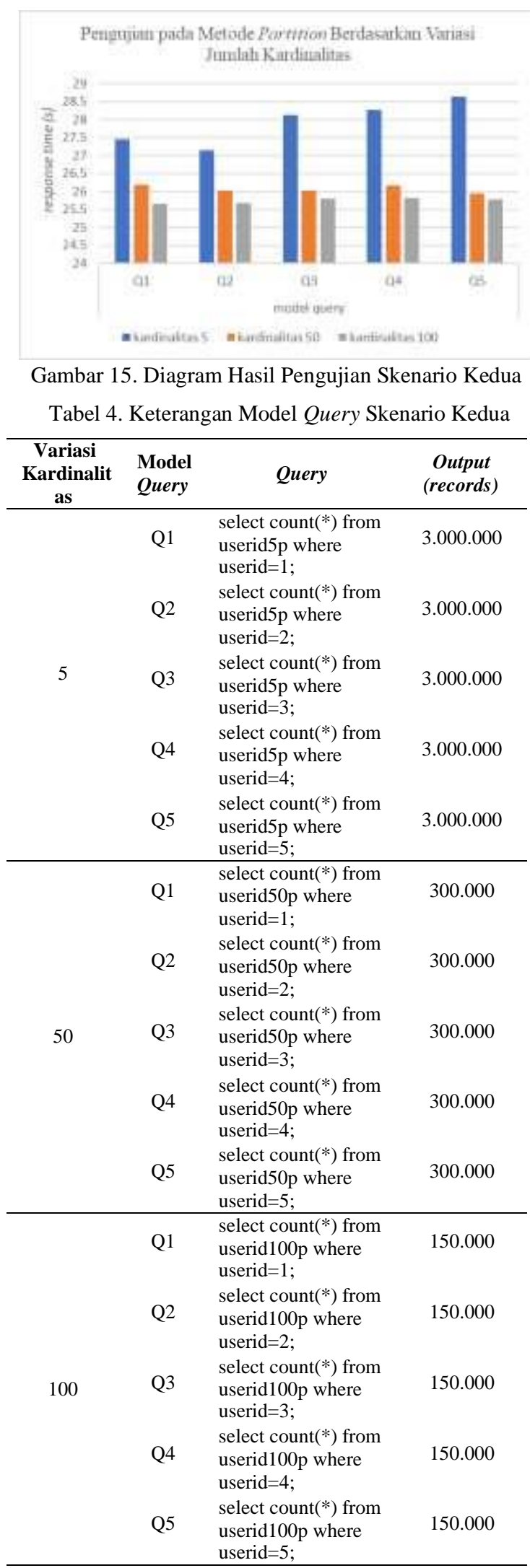

Dari pengujian yang telah dilakukan, terlihat bahwa pada kardinalitas 100 memberikan performansi response time query yang lebih cepat dibandingkan dengan kardinalitas 50 dan kardinalitas 5. Persentase rata-rata response time query pada kardinalitas
100 mengalami penurunan sebesar $1.24 \%$ dari kardinalitas 50, sedangkan persentase rata-rata response time query pada kardinalitas 100 mengalami penurunan sebesar $7.76 \%$ dari kardinalitas 5. Hal ini bisa terjadi karena pada kardinalitas 100, hasil eksekusi query (output) lebih kecil (150.000 records) dibandingkan pada variasi kardinalitas 5 dan 50 (masingmasing 3.000.000 records dan 300.000 records), kardinalitas 100 lebih baik.

\section{KESIMPULAN}

Berdasarkan dari hasil penelitian yang telah dilakukan, dapat disimpulkan bahwa metode partition selain mampu mengelompokkan data pada Hadoop-Hive, juga memberikan performansi response time query yang lebih cepat sebesar $30.8 \%$ dibandingkan kondisi default. Jika data terdiri dari jumlah records yang sama tetapi atribut berbeda kardinalitas, dari yang sudah diujicobakan metode partition pada kardinalitas 100 memberikan performansi response time query yang lebih baik dibandingkan pada dua kardinalitas lainnya yang lebih kecil yaitu kardinalitas 5 dan kardinalitas 50. Untuk implementasi metode partition, dapat diterapkan pada kondisi data yang terpartisi terdistribusi merata, sehingga kecepatan response time query pada tiap uniq values dari atribut akan tidak berbeda jauh.

\section{UCAPAN TERIMA KASIH}

Penulis mengucapkan banyak terima kasih kepada Allah SWT, kedua orang tua, saudara, dan khususnya kepada kedua dosen pembimbing, serta seluruh dosen Teknik Elektro terutama Program Studi Teknik Komputer dan Jaringan.

\section{REFERENSI}

[1] A. Gupta, M. Saxena, and R. Gill, "Performance Analysis of RDBMS and Hadoop Components with Their File Formats for the Development of Recommender Systems," 2018 3rd Int. Conf. Converg. Technol. I2CT 2018, pp. 1-6, 2018.

[2] M. Asha Kiran M and Sreedevi, "Hive Based Geospatial Analysis for Tracking and Envisioning of Geospatial Data in Hadoop Environment," no. 6, pp. 570573, 2019. 
[3] J. Mariam, “An Experimental Study On Different Data Models In Apache Hive," vol. 6, no. 7, pp. 43-51, 2019.

[4] T. A. Ashwitha, A. P. Rodrigues, and N. N. Chiplunkar, "Movie Dataset Analysis using Hadoop-Hive," 2017 2nd Int. Conf. Comput. Syst. Inf. Technol. Sustain. Solut., pp. 1-5, 2017.

[5] A. S. Kumar, "Performance Analysis of MySQL Partition , Hive PartitionBucketing and Apache Pig," 2016.

[6] A. Ramadhana and I. Krisnadi, "Identifikasi Strategi Pendekatan Big Data Yang Tepat Dalam Perusahaan,"

[7] Y. Huai et al., "Major technical advancements in Apache Hive," Proc. ACM SIGMOD Int. Conf. Manag. Data, pp. 1235-1246, 2014.

[8] T. DataFlair, "Hive Data Model Learn to Develop Data Models in Hive," 2020. [Online]. Available: https://data-flair.training/blogs/hivedata-model/.

[9] A. Thusoo et al., "Hive - A petabyte scale data warehouse using hadoop," Proc. - Int. Conf. Data Eng., pp. 9961005, 2010. 